\title{
Estimation of Thyroid Hormones
}

\section{Levels \& Lung Function in Conventional Radiotherapy of Breast, Head and Neck Cancer's}

\author{
Mohammed A. Ali Omer ${ }^{1,2}$, Abdulrahman A. S. Alsayyari' ${ }^{1}$, Abdullah Mohammed Aldokhail ${ }^{1}$, \\ Nasraldeen Alnaeem M. Alkhidir ${ }^{1}$
}

${ }^{1}$ Department of Radiologic Technology, College of Applied Medical Science, Qassim University, Buraidah, KSA
${ }^{2}$ College of Medical Radiologic Sciences, Sudan University of Science and Technology, Khartoum, Sudan
Email: ma.omer@qu.edu.sa, a.alsayyari@qu.edu.sa, am.abdullah@qu.edu.sa, nasro999@gmail.com

How to cite this paper: Ali Omer, M.A., Alsayyari, A.A.S., Aldokhail, A.M. and Alkhidir, N.A.M. (2019) Estimation of Thyroid Hormones Levels \& Lung Function in Conventional Radiotherapy of Breast, Head and Neck Cancer's. Open Journal of Radiology, 9, 194-205.

https://doi.org/10.4236/ojrad.2019.94018

Received: December 9, 2019

Accepted: December 24, 2019

Published: December 27, 2019

Copyright $\odot 2019$ by author(s) and Scientific Research Publishing Inc. This work is licensed under the Creative Commons Attribution International License (CC BY 4.0). http://creativecommons.org/licenses/by/4.0/

\begin{abstract}
Consequences of breast, head and neck cancers (HNC) radiotherapy are common among developing country patients; hence the aim of this work was to assess the impact of HNC (nasopharyngeal, laryngeal and hypopharyngeal and parotid) radiotherapy in thyroid and lungs functions. The data (tumor dose, dose histogram) has been retrieved from treatment planning system (TPS) and the thyroid hormones $\left(\mathrm{T}_{3}, \mathrm{~T}_{4}\right.$ and $\mathrm{TSH}$ ) level pre/post radiotherapy was measured by radioimmunoassay (RIA) technique. Ages (18 - 55 for HNC and 20 - 65 for breast cancer) derived from PACS and respiratory rate (RR) assessed by counting the number of breathing/minutes. The analyzed data using Excel showed that: the impact of HNC without parotid and supraclavicular irradiation was significant $(\mathrm{P}=0.00)$ reduction on $\mathrm{T}_{3} \& \mathrm{~T}_{4}$, and increasing TSH hormones relative to applied tumor dose. The average doses $(2.8,30,32,33$ and $20.5 \mathrm{~Gy})$ received by thyroid gland from irradiation of parotid, larynx, breast, hypopharynx and nasopharynx respectively reduced $\mathrm{T}_{4} / \mathrm{T}_{3}$ hormones to $125.9 / 0.8,109 / 0.6,67.8 / 0.4,33.9 / 0.3$ and $105.8 / 0.7$ respectively and increased TSH to $4.5,6.3,8.1,11.5$ and $0.65 \mathrm{mU} / 1$ respectively. The $\mathrm{RR}$ increased significantly $(\mathrm{P}=0.05)$ from $19.1 \pm 3.6$ to $22.1 \pm 3.4$ in average due to tangential fields irradiation of breast. Conclusion addressing that: conventional radiotherapy for HNC \& breast induce a significant reduction in thyroid hormones and increment of RR.
\end{abstract}

\section{Keywords}

Breast, Head, Neck, Radiotherapy, Thyroid, Lungs 


\section{Introduction}

The malignant tumors originated in head and neck representing 9th most common cancer and threatening diseases where being disseminated over the world which striking throat, larynx, hypopharynx, nasopharynx, nose, sinuses, parotid and mouth [1] that denoted by head and neck cancer (HNC). The annual incidence had been estimated between 400,000 - 600,000 and mortality rate between 223,000 - 300,000 deaths/year [2]. Regionally, these malignancies represented the most top ten in South East Asia and India [3] [4]. Among these cancers; nasopharyngeal carcinoma (NPC) showed a rising rate in Asia, Middle East, North Africa and peaked in Southern China [5]. In Saudi Arabia, NPC has been decreased by a factor of $2.9 \%$ annually since 1990 with mortality value of 0.68 deaths per 10,000 men in 2013, which was higher compared among women as 0.33 per 10,000 women [6]. It ranked at 18 with an incidence of $1.7 \%$ based on international classification of diseases 2018 [7]. The encouraging aspect for considering NPC is its consequences, late discovery among Saudis' population (70\% of patients presented with stage III and IV) [6] [8] and the induced hypothyroidism due to conventional radiation therapy.

In Sudan, NPC represented 6\% of all cancer cases based on Sudan Cancer Registry (SCR) records, and 7\% based on Radiation Isotope Center-Khartoum (RICK) and having a male to female ratio of 2.6:1 respectively [8]. The recent Sudan cancer registry (2018) showed that: NPC ranked at 17 and the incidence as $1.8 \%$. The patients with NPC presented for medication with advanced stages as $68 \%, 65.97 \%$, and $15.58 \%$ for stage IV, III, and II respectively [9]. Also, Laryngeal cancer is ranked at the 14th most common cancer worldwide and it is the most common cancer among HNC [8]. In Sudan during 2014-2016, Laryngeal cancer represents $95.1 \%$ as common among Sudanese male as well as reported by other scholars [10] [11] [12]. In Saudi Arabia, it ranked at 25 with an incidence of $0.63 \%$ in 2018 based on international classification of diseases 2018 [7]. Hypopharyngeal carcinoma (HPoPC) (carcinoma originated at pharyngoesophageal junction (postcricoid), pyriform fossa, and posterior pharyngeal wall) has been encountered in radiation centers in Saudi Arabia and represented 0.2\%. The involved anatomical parts showed $28.3 \%$ and $19.9 \%$ and $52.9 \%$, for post-cricoid, pyriform fossa and both sites respectively. It has a survival rate of $16 \%-25 \%$ irrespective to treatment models such as surgery and radiation therapy [13]. And it ranked at 29 with an incidence of $0.21 \%$ based on international classification of diseases 2018 [7]. While in Sudan, it ranked at 27 with an incidence of $0.44 \%$. However, it has been increasing in western regions of Sudan (Dilling, Kadogli and Nuba Mountains) and predominantly among the ages of $15-19$ years and one at $50-54$ years with male to female ratio of 2.6:1. The common presented cases for treatment represented stage II (15.58\%) and III (65.97\%) [9].

Breast cancer represents one of the most top common cancers among Saudi women with $21.8 \%$ [14]. In recent survey of cancer-related mortality among Saudi women; breast cancer represented as the 9th leading cause of death [15] [16]. 
While Ibrahim et al. [17] predicted that: the incidence percent of breast cancer will increase over the next few decades as the population grows and ages. Comparing that with Sudan; breast cancer has been representing as top (ranked at 1) most common cancer among Sudanese female with incidence of $22.1 \%$. It has been managed by different treatment modalities such as surgery, radiotherapy, chemotherapy and hormonal therapy [18]. The radiotherapy (RT) is commonly given to eradicate the residual microscopic cancer cells after operation or for palliation or adjuvant treatment, hence commonly accompanied by radiation sickening extended from mild to severe side effects. The side effects under focus in this research are the physiological effects of thyroid gland and the lung due to external radiotherapy of the HNC and the breast cancers. Thyroid dysfunction commonly develops after ionizing radiation therapy at therapeutic doses 225 $4300 \mathrm{cGy}$ [19]. Also, in the same realm, Bonato et al. [20] have reported that: the hypothyroidism is very common in survivors of childhood cancer treated with external beam radiation. In the study carried out by Laway et al. [21]; they showed that: the primary hypothyroidism often develops as a result of radiotherapy to the cervical region in therapeutic doses (30 - 70 Gy) in patients with head and neck cancer and the mean time for development of hypothyroidism was 4.5 months. Relative to radiation effect in the lungs that maintaining the level of oxygen and carbon dioxide in arterial blood, some scholars [22] [23] [24] revealed that: breast cancer irradiation leading to pneumonitis of Grade I (16\%) and II (4.9\%) after 6 months of RT course. And more over: Lopez et al. [25] showed a reduction in lung diffusing capacity for carbon monoxide (DLCO) among the majority of the patients after RT with modern techniques which furtherly affecting the mean normal respiratory rate (MRR) which is 19 breath/minute [26].

Therefore, the main focus of this work is on the accompanied hypothyroidism and respiratory incompetence due to HNC \& breast irradiation respectively. And the general objective of this study is to correlate the level of thyroid hormones $\left(\mathrm{T}_{3}, \mathrm{~T}_{4}, \mathrm{TSH}\right)$ with the applied prescribed carcinocidal radiation dose, determine the hormones level at specific committed radiation dose in addition to RR after Nasopharyngeal, hypo-pharyngeal, laryngeal, parotid and breast carcinoma with respect to applied conventional radiotherapy technique.

\section{Method}

The following research conducted as a retrospective study targeting the patients underwent RT course and have been examined for white blood count WBC, red blood cells (RBCs), respiratory rate and further for thyroid hormones. The relevant data have been accessed and retrieved from picture archiving computerized System (PACS) of cancer treatment centers after signature of the informed consent by the patients and based on the approval of the ethical committee of the University addressed to hospitals. The total samples were 80 patients for nasopharyngeal, laryngeal, hypo-pharyngeal, and Parotid carcinomas and 100 patients for breast cancer. The sample ages were 18 - 55 for HNC and $20-65$ years for breast cancer. The target volumes with relative radiation field sizes verified 
by using simulator and pentogram shown in Figure 1. The radiation dose received by thyroid gland retrieved from the dose histogram obtained by PlanWTreatment Planning System for Radiotherapy (Version 3.0.2017) with its quality controlled verified based on Benedick et al. [27] and IAEA [28] method. The applied prescribed carcinocidal doses were 4500 - 5250 cGy for breast cancer, 6000 6500 cGy for nasopharyngeal, laryngeal/hypo-pharyngeal and Parotid carcinomas. The RT machine used for irradiation was 60 co-teletherapy machine with conventional collimator.

Thyroid hormones: Tri/tetra iodothyronine and Thyroid Stimulating Hormone (T3, T4, TSH) have been measured from the withdrawal blood samples as $15 \mathrm{cc}$ from each patient using disposable syringe and collected in three dry glass tubes $(5 \mathrm{cc} /$ tube for each patient) with anticoagulant and immediately centrifuged at $2000 \mathrm{rpm}$ (rotation per minutes) for 5 minutes and the amount of separated serum assessed by using Radio-immunoassay kits (DPC, USA) on Gammamatic II gamma counter (Contron, Switzerland) to determine the amount of T3, T4 and TSH for all cases pre/post radiotherapy course, and as well the WBC and RBCs that stored in patient's file in PACS.
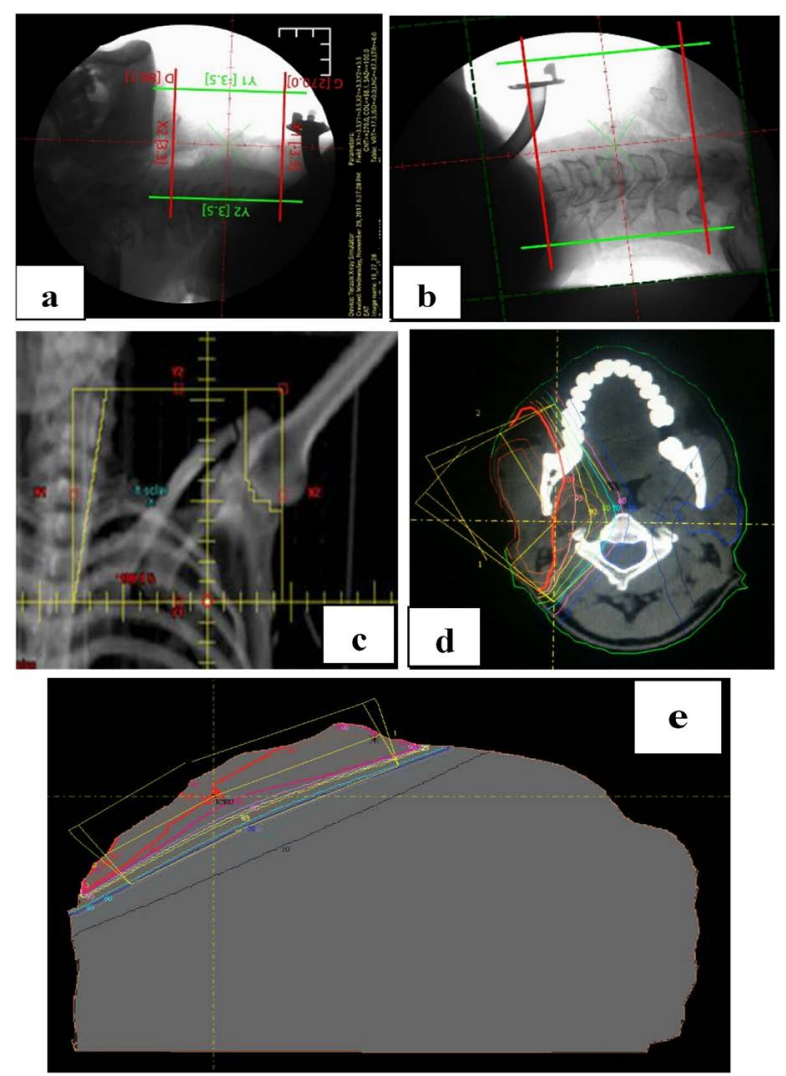

Figure 1. Simulation images showed (a) Larynx simulation two opposing fields sparing the tracheostomy, (b) hypopharynx simulation two opposing fields including the posterior cervical lymph nodes, (c) anterior supraclavicular simulation field targeting supra/infra-clavicular and cervical lymph nodes, (d) CT image of parotid gland and (e) pentagram for breast tangential fields with dose histogram done by PlanW-Treatment Planning System. 


\section{Results}

The results present the scattered plot correlation for received dose in cGy versus thyroid hormone level for irradiated HNC and breast (Figures 1-5), while Figure 6 shows the average dose received by thyroid gland from each irradiated case versus the level of thyroid hormones $\left(\mathrm{T}_{3}, \mathrm{~T}_{4}\right.$, and TSH). Figure 7 presents the correlation of respiratory rate (RR) versus ages of patient's pre/post radiotherapy course.

\section{Discussion}

Up to date, the conventional radiotherapy has been a common and main technique to eradicate the residual cancer cells post operation, and further could be given as pre-operation (enhancing operation technique) or palliative treatment in developing countries. However, the consequences due to irradiation still

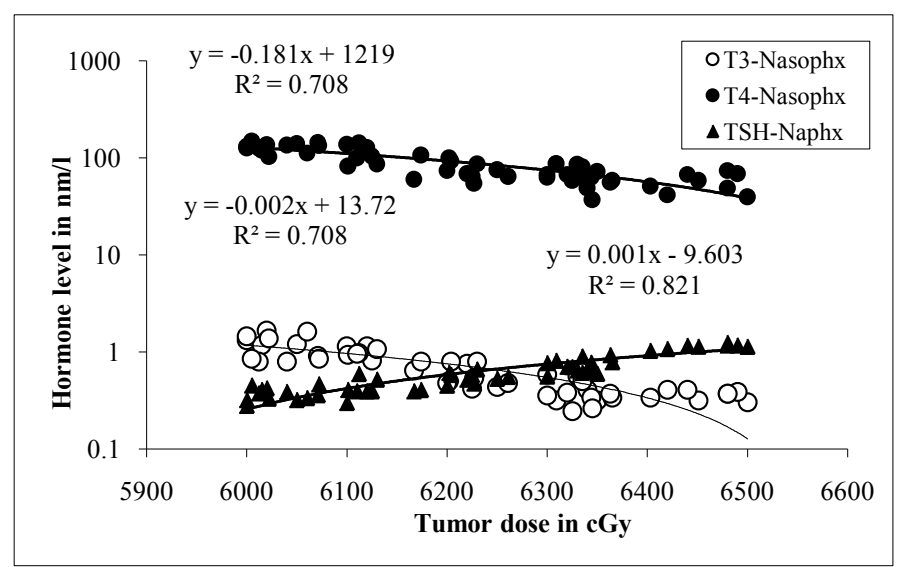

Figure 2. The correlation between the applied prescribed carcinocidal radiation dose for nasopharyngeal carcinoma and the relative thyroid hormones level as a reduction impact on $\mathrm{T}_{3}$ and $\mathrm{T}_{4}$ and increasing impact on TSH levels.

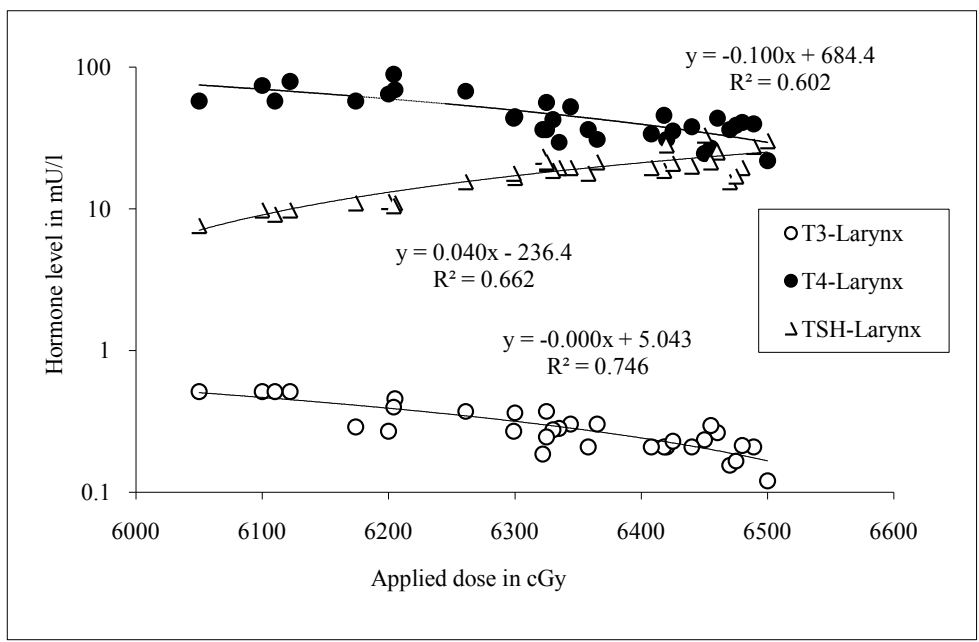

Figure 3. The applied prescribed carcinocidal radiation doses for Laryngeal carcinoma irradiation and the relative thyroid hormonal level as a reduction impact on $\mathrm{T}_{3}$ and $\mathrm{T}_{4}$ and increasing impact on TSH levels. 


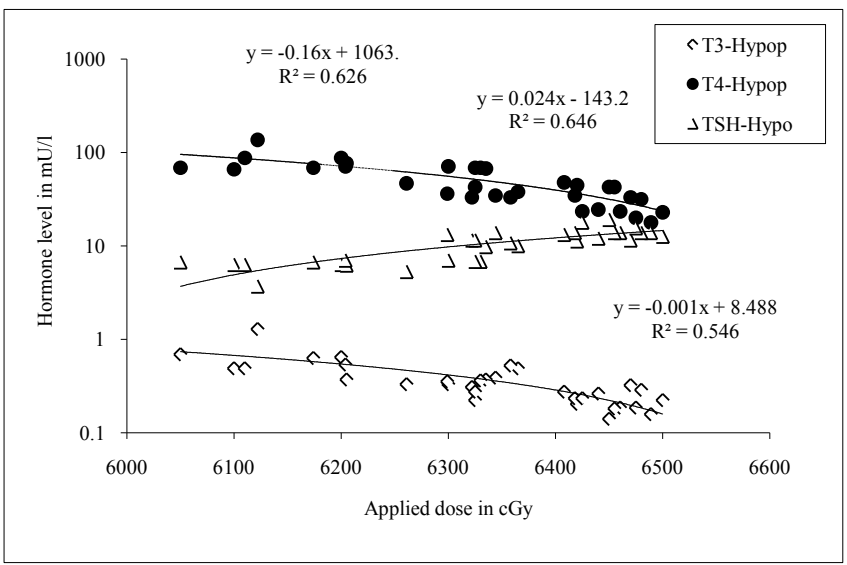

Figure 4. The applied prescribed carcinocidal radiation doses for Hypopharyngeal carcinoma irradiation and relative thyroid hormonal level as a reduction impact on $\mathrm{T}_{3}$ and $\mathrm{T}_{4}$ and increasing impact on TSH levels.

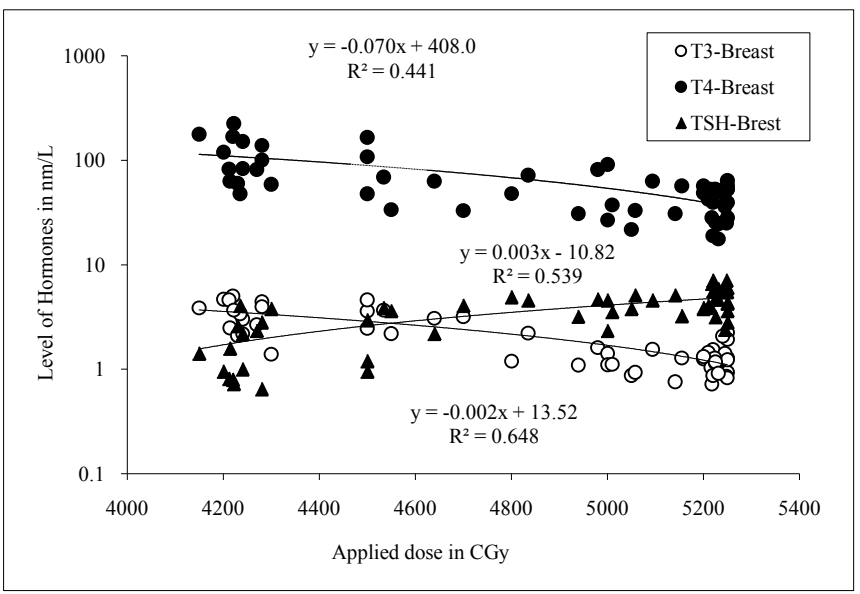

Figure 5. The applied prescribed carcinocidal radiation doses for supraclavicular field of (targeting cervical, supra/infra clavicle and axillary lymph nodes) breast carcinoma irradiation and relative thyroid hormonal levels as a reduction impact on $\mathrm{T}_{3}$ and $\mathrm{T}_{4}$ and increasing impact on TSH levels.

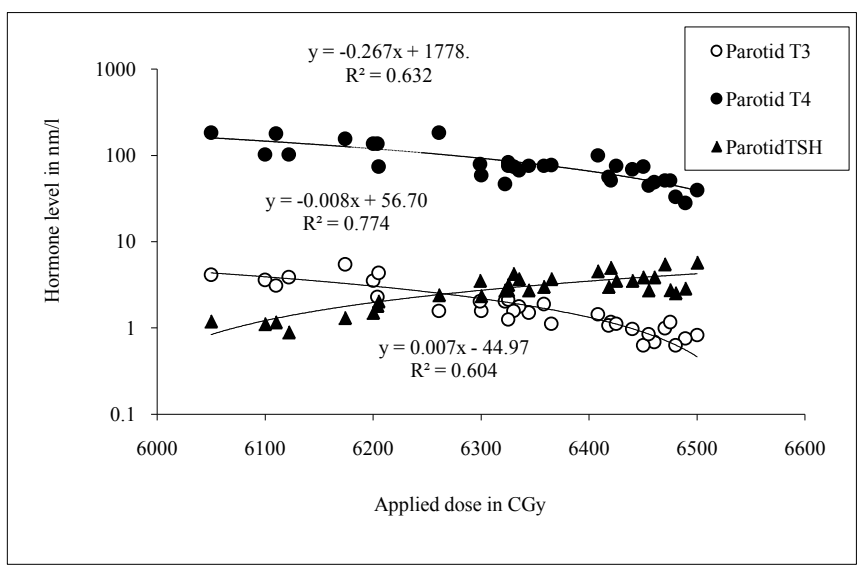

Figure 6. The applied prescribed carcinocidal radiation doses for Parotid carcinoma irradiation and the relative thyroid hormonal level as a reduction impact on $\mathrm{T}_{3}$ and $\mathrm{T}_{4}$ and increasing impact on TSH levels. 


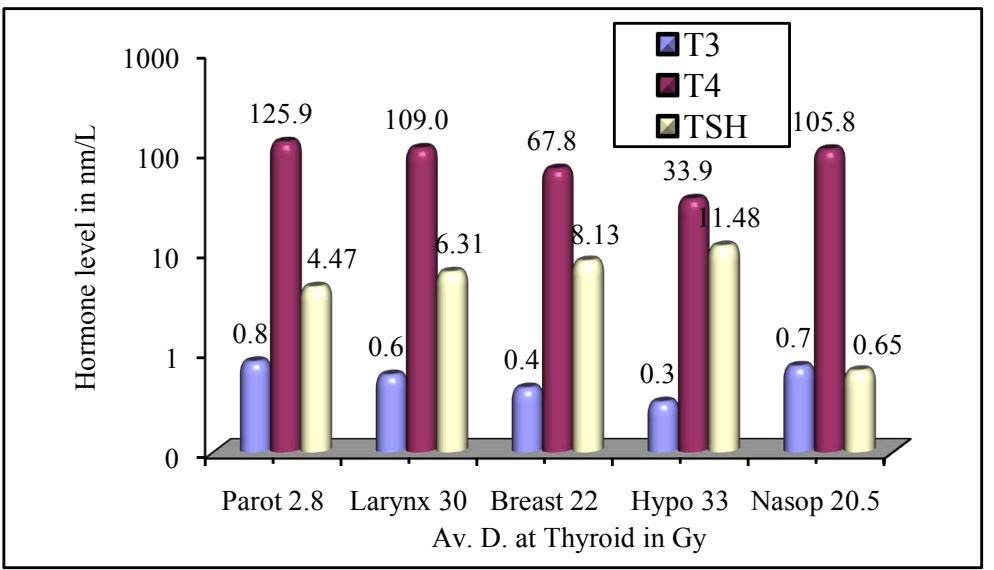

Figure 7. The average dose received by thyroid gland from each irradiated case (Parotid, Larynx, Breast, Hypopharynx and Nasopharynx) and the relative level of thyroid hormones (T3, T4, and TSH).

prominent and turning the scholar's attention. Figures 2-6 show the correlation between the applied tumor dose for HNC and the relative influenced hormonal levels in logarithmic scale. In which thyroid hormones T4 and T3 decreased significantly $(\mathrm{R} 2=0.7$ and 0.8$)$ in a linear form following the radiation dose increment as correlated in equations: $y=-0.1816 x+1219$ and $y=-0.0021 x+13.724$ respectively and TSH increased significantly $(\mathrm{R} 2=0.8)$ following the radiation dose increment as correlated in equation: $y=0.0016 x-9.6036$, for nasopharyngeal irradiation. For laryngeal irradiation, the correlations were fitted to equations: $\mathrm{y}=-0.1008 \mathrm{x}+684.42$ and $\mathrm{y}=0.0402 \mathrm{x}-236.43\left(\mathrm{~T}_{4}\right.$ and $\left.\mathrm{T}_{3}\right)$ and $\mathrm{y}=$ $-0.0008 \mathrm{x}+5.0432(\mathrm{TSH})$. For hypopharyngeal irradiation, the correlations were fitted to equations: $\mathrm{y}=-0.16 \mathrm{x}+1063.3$ and $\mathrm{y}=0.0243 \mathrm{x}-143.22$ (T4 and T3) and $y=-0.0013 x+8.4887$ (TSH). For supraclavicular of breast irradiation, the correlations were fitted to equations: $y=-0.0708 x+408.05$ and $y=0.003 x-$ $10.825\left(\mathrm{~T}_{4}\right.$ and $\left.\mathrm{T}_{3}\right)$ and $\mathrm{y}=-0.0024 \mathrm{x}+13.527(\mathrm{TSH})$. For parotid gland irradiation, the correlations were fitted to equations: $\mathrm{y}=-0.2677 \mathrm{x}+1778.9$ and $\mathrm{y}=$ $-0.0087 \mathrm{x}+56.702\left(\mathrm{~T}_{4}\right.$ and $\left.\mathrm{T}_{3}\right)$ and $\mathrm{y}=0.0076 \mathrm{x}-44.97(\mathrm{TSH})$, where $\mathrm{x}$ refers to radiation dose in $\mathrm{cGy}$ and $\mathrm{y}$ refers to the level of hormones in $\mathrm{nmol} / \mathrm{l}$ for all correlated equations. The t-test has been carried out for the level of hormones pre/post irradiation with references to normal levels (T3: 0.8 - $3.0 \mathrm{nmol} / \mathrm{L}, \mathrm{T} 4$ : $50-150 \mathrm{nmol} / \mathrm{L}$, TSH: $0.4-4.0 \mathrm{mu} / \mathrm{L}$ ) which was showed significant impact at $\mathrm{P}=$ 0.00 , for nasopharyngeal, larynx, hypopharynx and $\mathrm{P}=0.05$ for breast and parotid gland irradiation. The reduction of hormones could be ascribed to damage or inhibition of the active follicular epithelium and reduce the number of functional follicles; or it may reduce the vascular permeability or may trigger immunologic reactions leading to histological changes, as reported by Mizukami et al. [29]. Also, Jung et al., [30] showed that: numerous numbers of abnormal small follicles were observed in the thyroid tissues of rats which were surrounded by cuboidal or columnar epithelium on days 4 and 7 after irradiation and inflammatory cells were observed in the inter-follicular areas. While Chougule and 
Kochar [31] found that the levels of $\mathrm{T}_{4} \& \mathrm{~T}_{3}$ were decreased significantly ( $\mathrm{p}<$ $0.001, p<0.005$ after irradiation. In previous studies, scholars [32] [33] [34] stated that: the HNC irradiation results in hypothyroidism in at least $50 \%$ of patients. The increment of TSH could be ascribed to a reduced level of T4 and T3 in the circulating blood that triggers and stimulate the production of TSH by the pituitary gland.

In supraclavicular irradiated field for breast, despite the radiation field was partially encompassing the thyroid gland compared with the cases of HNC however the impact was so significant due to large penumbra profile of the $60 \mathrm{Co}$ source of teletherapy machine as well as inadequate shielding during radiotherapy session which furtherly led to shoulder joint stiffness for some patients.

The radiation dose received by thyroid gland Figure 7, due to Nasopharynx, parotid, larynx, breast and hypopharynx irradiation were 20.5, 2.8, 30, 22 and 33 Gy respectively that reducing significantly $(\mathrm{p}=0.00-0.05)$ the thyroid hormone $\mathrm{T}_{3}$ to $(0.7,0.8,0.6,0.4,0.3)$ and $\mathrm{T}_{4}$ to $(105.8,125.9,109,67.8,33.9)$ and $\mathrm{TSH}$ to $(0.7,4.5,6.3,8.1,11.5)$ respectively. Such results agreed with study done by Reinertsen et al. [35] and Smith et al. [36] where they noticed about $18 \%$ and $14 \%$ of the patients developed post radiotherapy hypothyroidism respectively due to 31 Gy average dose.

Based on the literature highlighted by Johansen et al. [37]; Ahmed et al. [38] and Chaurasia et al. [39]; the impact of irradiation in thyroid depends on volume of the thyroid, applied dose for cancer case, fields distribution, planning method, applied technique and the type of radiotherapy machine in addition to gender and the age. The general HNC irradiation has been noticed to cause hypothyroidism among $48 \%$ of patients underwent radiotherapy course [40]. According to such findings, the applied radiotherapy technique and the number of radiation fields distribution have to be verified seriously with usage of modern treatment planning systems with multi-leave collimators facilities and the worth to be recommended is the usage of intensity modulated radiation therapy (IMRT) as it gives modular radiation intensity concise with the tumor density and thickness in addition to precise shaping of the radiation field relative to tumor extension and sparing the adjacent vital organs.

The respiratory rate (RR) pre/post radiotherapy course has been assessed based on the number of inspirations per minute by direct observation of the patient chest wall rises and falls. The scattered plot (Figure 8) showed significant $(\mathrm{P}=0.00)$ increment of $\mathrm{RR}(22.1 \pm 3.4)$ post radiotherapy course (average received dose 12.6 Gy from tangential fields, patient supine) compared with $19.1 \pm$ 1.6 breath/minute before irradiation (Normal $\mathrm{RR}=20$ breath/minute [41]. Further side effects noticed among the patients were coughing and shoulder joint stiffness. The procedure of radiation therapy adjacent to thyroid gland and lung better implemented using intensity modulated radiation therapy IMRT or even volumetric modulated arc therapy that would not lead to such a significant radiation effect [42]. 


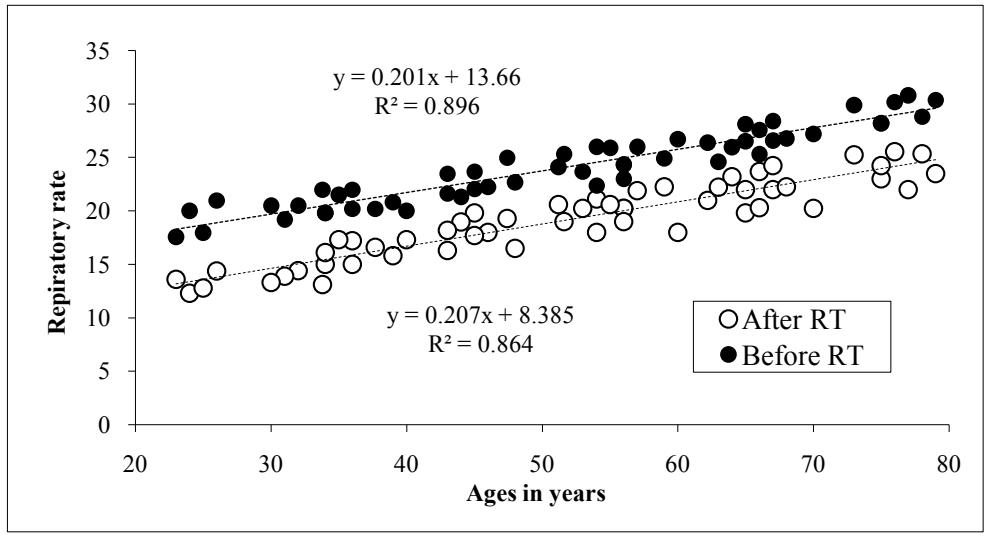

Figure 8. Shows the scattered plot to correlate between age in years and respiratory rate for irradiated patients ( $\mathrm{Ca}$. breast tangential fields) pre and after RT course, tumor dose 45005000 cGy.

\section{Conclusion}

The conclusion addressing that: conventional radiotherapy for HNC \& breast induce a significant reduction in thyroid hormones and increment of RR, leading to the necessity of using IMRT.

\section{Acknowledgements}

The authors gratefully acknowledge Qassim University represented by the Deanship of Scientific Research, on the material support for this research under the number [CAMS 1-2018-1-14-S-3555] during 1440 H/2018 AD.

\section{Conflicts of Interest}

The authors declare no conflicts of interest regarding the publication of this paper.

\section{References}

[1] Ferlay, J., Soerjomataram, I., Ervik, M., Dikshit, R., Eser, S., Mathers, C., Rebelo, M., Parkin, D.M., Forman, D. and Bray, F. (2013) GLOBOCAN 2012 v1.0, Cancer Incidence and Mortality Worldwide: IARC Cancer Base No. 11 [Internet]. International Agency for Research on Cancer, Lyon.

[2] Chaturvedi, A.K., Anderson, W.F., Lortet-Tieulent, J., et al. (2013) Worldwide Trends in Incidence Rates for Oral Cavity and Oropharyngeal Cancers. Journal of Clinical Oncology, 31, 4550-4559. https://doi.org/10.1200/JCO.2013.50.3870

[3] Jemal, A., Bray, F., Center, M.M., et al. (2011) Global Cancer Statistics. CA: A Cancer Journal for Clinicians, 61, 69-90. https://doi.org/10.3322/caac.20107

[4] Krishna Rao, S.V., Mejia, G., Roberts-Thomson, K., et al. (2013) Epidemiology of Oral Cancer in Asia in the Past Decade: An Update (2000-2012). Asian Pacific Journal of Cancer Prevention, 14, 5567-5677. https://doi.org/10.7314/APJCP.2013.14.10.5567

[5] Chang, E.T. and Adami, H.-O. (2006) The Enigmatic Epidemiology of Nasopharyngeal Carcinoma. Cancer Epidemiology, Biomarkers \& Prevention, 15, 1765-1777. https://doi.org/10.1158/1055-9965.EPI-06-0353 
[6] Alotaibi, A.D., Ahmed, H.G. and Elasbali, A.M. (2019) Nasopharyngeal Cancer in Saudi Arabia: Epidemiology and Possible Risk Factors. Journal of Oncological Sciences, 5, 23-30. https://doi.org/10.1016/j.jons.2019.01.002

[7] Al-Shahrani, Z.S., Al-Rawaji, A.I., Al-Madouj, A.N. and Hayder, M.S. (2017) Saudi Cancer Registry-Cancer Incidence Report Saudi Arabia 2014. Saudi Health Council-KSA.

[8] Zhang, L., Zhao, C., Ghimire, B., et al. (2010) The Role of Concurrent Chemoradiotherapy in the Treatment of Locoregionally Advanced Nasopharyngeal Carcinoma among Endemic Population: A Meta-Analysis of the Phase III Randomized Trials. BMC Cancer, 10, 558. https://doi.org/10.1186/1471-2407-10-558

[9] Abdullah, N.E., Adam, A.A.M., Khalifa, E.H., El Hassan, L.A.M., Ibrahim, M.E., Hamad, K.M. and El Hassan, A.M. (2011) Nasopharyngeal Cancer in Sudan: Epidemiology, Clinical and Histological Characteristics. Clinical Medicine Insights. Ear, Nose and Throat, 4, 5-11. https://doi.org/10.4137/CMENT.S5825

[10] Villanueva-Reyes, A., Strand, E., Nazario, C.M. and Irizarry-Ramirez, M. (2008) Cancer of the Larynx in Puerto Rico. Puerto Rico Health Sciences Journal, 27, 196-203.

[11] Ahmed, S., Abdelrhman, S., Taha, M., Malik, M. and El Naseh, W. (2018) Etiology and Clinical Presentation of Laryngeal Cancer in Sudanese Patients. International Journal of Otolaryngology, 5, 3. https://doi.org/10.13188/2380-0569.1000022

[12] Jones, T.M., De, M., Foran, B., Harrington, K. and Mortimore, S. (2016) Laryngeal Cancer: United Kingdom National Multidisciplinary Guidelines. The Journal of Laryngology \& Otology, 130, S75-S82. https://doi.org/10.1017/S0022215116000487

[13] Kajanti, M. and Manty, A. (1990) Carcinoma of the Hypopharynx. A Retrospective Analysis of the Treatment Result Over a 25-Year Period. Acta Otologica, 29, 903-907.

[14] Mahasin, Z. and Khan, B. (1996) Hypopharyngeal Carcinoma: King Faisal Specialist Hospital and Research Centre Experience. Annals of Saudi Medicine, 16, 539-544. https://doi.org/10.5144/0256-4947.1996.539

[15] Alotaibi, R.M., Rezk, H.R., Juliana, C.I. and Guure, C. (2018) Breast Cancer Mortality in Saudi Arabia: Modelling Observed and Unobserved Factors. PLoS ONE, 13, e0206148. https://doi.org/10.1371/journal.pone.0206148

[16] Ayadi, W., Khabir, A., Hadhri-Guiga, B., et al. (2010) North African and Southeast Asian Nasopharyngeal Carcinomas: Between the Resemblance and the Dissemblance. Bulletin du Cancer, 97, 475-482. https://doi.org/10.1684/bdc.2010.1090

[17] Nguyen-Van, D., Ernberg, I., Phan-Thi Phi, P., Tran-Thi, C. and Hu, L. (2008) Epstein-Barr Virus Genetic Variation in Vietnamese Patients with Nasopharyngeal Carcinoma: Full-Length Analysis of LMP1. Virus Gene, 37, 273-281. https://doi.org/10.1007/s11262-008-0262-9

[18] Ibrahim, E.M., Zeeneldin, A.A., Sadiq, B.B. and Ezzat, A.A. (2008) The Present and the Future of Breast Cancer Burden in the Kingdom of Saudi Arabia. Medical Oncology, 25, 387-393. https://doi.org/10.1007/s12032-008-9051-5

[19] Elamin, A., Ibrahim, M.E., Abuidris, D., Mohamed, K.E.H. and Mohammed, S.I. (2015) Part I: Cancer in Sudan-Burden, Distribution, and Trends Breast, Gynecological, and Prostate Cancers. Cancer Medicine, 4, 447-456. https://doi.org/10.1002/cam4.378

[20] Fuks, Z., Glatstein, E., et al. (1976) Long-Term Effects of External Radiation on the Pituitary and Thyroid Glands. Cancer, 37, 1152-1161.

https://doi.org/10.1002/1097-0142(197602)37:2+<1152::AID-CNCR2820370826>3.0 .CO;2-T 
[21] Bonato, C., Severino, R.F. and Elnecave, R.H. (2008) Reduced Thyroid Volume and Hypothyroidism in Survivors of Childhood Cancer Treated with Radiotherapy. Journal of Pediatric Endocrinology and Metabolism, 21, 943-949. https://doi.org/10.1515/JPEM.2008.21.10.943

[22] Laway, B.A., Shafi, K.M., Majid, S., Lone, M.M., Afroz, F., Khan, S. and Roohi, R. (2012) Incidence of Primary Hypothyroidism in Patients Exposed to Therapeutic External Beam Radiation, Where Radiation Portals Include a Part or Whole of the Thyroid Gland. Indian Journal of Endocrinology and Metabolism, 16, 329-331.

[23] Jaén, J., Vázquez, G., Alonso, E., León, A., Guerrero, R. and Almansa, J.F. (2006) Changes in Pulmonary Function after Incidental Lung Irradiation for Breast Cancer: A Prospective Study. International Journal of Radiation Oncology, Biology, Physics, 65, 1381-1388. https://doi.org/10.1016/j.ijrobp.2006.03.008

[24] Hernberg, M., Virkkunen, P., Maasilta, P., Keyriläinen, J., Blomqvist, C., Bergh, J., et al. (2002) Pulmonary Toxicity after Radiotherapy in Primary Breast Cancer Patients: Results from a Randomized Chemotherapy Study. International Journal of Radiation Oncology, Biology, Physics, 52, 128-136. https://doi.org/10.1016/S0360-3016(01)01760-6

[25] Lopez Guerra, J.L., Gomez, D.R., Zhuang, Y., Levy, L.B., Eapen, G., Liu, H.M., Mohan, R., Komaki, R., Cox, J.D. and Liao, Z.X. (2012) Changes in Pulmonary Function after Three-Dimensional Conformal Radiation Therapy, Intensity-Modulated Radiation Therapy, or Proton Beam Therapy for Non-Small Cell Lung Cancer. International Journal of Radiation Oncology, Biology, Physics, 83, e537-e543. https://doi.org/10.1016/j.ijrobp.2012.01.019

[26] Subbe, C.P., Davies, R.G., Williams, E., et al. (2003) Effect of Introducing the Modified Early Warning Score on Clinical Outcomes, Cardio-Pulmonary Arrests and Intensive Care Utilisation in Acute Medical Admissions. Anaesthesia, 58, 797-802. https://doi.org/10.1046/j.1365-2044.2003.03258.x

[27] Benedick, F., Doppke, K., Hunt, M., Kutcher, G., Starkschall, G., Stern, R. and Van Dyke, J. (1998) AAPM Radiation Therapy Committee TG53: Quality Assurance Program for Radiotherapy Treatment Planning. Medical Physics, 25, 1773-1836. https://doi.org/10.1118/1.598373

[28] IAEA (2004) Commissioning and Quality Assurance of Computerized Planning Systems for Radiation Treatment of Cancer. TRS 430, Austria.

[29] Mizukami, Y., Michigishi, T., Nonomura, A., Hashimoto, T., Noguchi, M., Ohmura, K. and Matsubara, F. (1992) Histologic Changes in Graves' Thyroid Gland after ${ }^{131} \mathrm{I}$ Therapy for Hyperthyroidism. Acta Pathologica Japonica, 42, 419-426. https://doi.org/10.1111/j.1440-1827.1992.tb03247.x

[30] Jung, J.H., Jung, J., Kim, S.K., Woo, S.H., Kang, K.M., Jeong, B.-K., Jung, M.H., Kim, J.H. and Hahm, J.R. (2014) Alpha Lipoic Acid Atteuates Radiation-Induced Thyroid Injury in Rats. PLoS ONE, 9, e112253. https://doi.org/10.1371/journal.pone.0112253

[31] Chougule, A. and Kochar, B. (2011) Thyroid Dysfunction Following Therapeutic External Radiation to Head and Neck Cancer. Asian Pacific Journal of Cancer Prevention, 12, 443-445.

[32] Garcia-Serra, A., Amdur, R.J., Morris, C.G., Mazzaferri, E. and Mendenhall, W.M. (2005) Thyroid Function Should Be Monitored Following Radiotherapy to the Low Neck. American Journal of Clinical Oncology, 28, 255-258. https://doi.org/10.1097/01.coc.0000145985.64640.ac

[33] Fleming, I.D., et al. (1985) Thyroid Dysfunction and Neoplasia in Children Receiv- 
ing Neck Irradiation for Cancer. Cancer, 55, 1190-1194. https://doi.org/10.1002/1097-0142(19850315)55:6<1190::AID-CNCR2820550609>3. $\underline{0 . \mathrm{CO} ; 2-6}$

[34] Khoo, V.S., Liew, K.H., Crennan, E.C., D’Costa, I.M. and Quong, G. (1998) Thyroid Dysfunction after Mantle Irradiation of Hodgkin's Disease Patients. Australasian Radiology, 42, 52-57. https://doi.org/10.1111/j.1440-1673.1998.tb00565.x

[35] Reinertsen, K.V., Cvancarova, M., Wist, E., Bjøro, T., Dahl, A.A., Danielsen, T. and Fosså, S.D. (2009) Thyroid Function in Women after Multimodal Treatment for Breast Cancer Stage II/III: Comparison with Controls from a Population Sample. International Journal of Radiation Oncology, Biology, Physics, 75, 764-770. https://doi.org/10.1016/j.ijrobp.2008.11.037

[36] Smith, G.L., Smith, B.D., Giordano, S.H., Shih, Y.C., Woodward, W.A., Strom, E.A., Perkins, G.H., Tereffe, W., Yu, T.K. and Buchholz, T.A. (2008) Risk of Hypothyroidism in Older Breast Cancer Patients Treated with Radiation. Cancer, 112, 1371-1379. https://doi.org/10.1002/cncr.23307

[37] Johansen, S., Reinertsen, K.V., Knutstad, K., Olsen, D.R. and Fosså, S.D. (2011) Dose Distribution in the Thyroid Gland Following Radiation Therapy of Breast Cancer: A Retrospective Study. Radiation Oncology, 6, 68. https://doi.org/10.1186/1748-717X-6-68

[38] Ahmed, Z., Khan, M.A., Haq, A., Attaullag, S. and ur Rehman, Z. (2009) Effect of Race, Gender and Age on Thyroid and Thyroid Stimulating Hormone Levels in Northwest Frontier Province, Pakistan. Journal of Ayub Medical College Abbottabad, 21, 21-24.

[39] Chaurasia, P., Modi, B., Mangukiya, S., Jadav, P. and Shah, R. (2011) Variation of Thyroid Hormones Level among People of Different Age, Gender and Seasons, Piparia, Gujarat. National Journal of Medical Research, 1, 57-59.

[40] Mercado, G., Adelstein, D.J., Saxton, J.P., Secic, M., Larto, M.A. and Lavertu, P. (2001) Hypothyroidism: A Frequent Event after Radiotherapy and after Radiotherapy with Chemotherapy for Patients with Head and Neck Carcinoma. Cancer, 92, 2892-2897.

https://doi.org/10.1002/1097-0142(20011201)92:11<2892::AID-CNCR10134>3.0.C $\mathrm{O} ; 2-\mathrm{T}$

[41] Hong, W., Earnest, A., Sultana, P., et al. (2013) How Accurate Are Vital Signs in Predicting Clinical Outcomes in Critically Ill Emergency Department Patients. European Journal of Emergency Medicine, 20, 27-32. https://doi.org/10.1097/MEJ.0b013e32834fdcf3

[42] Goldman, B.U., Anderson, M., Wennberg, B. and Lind, P. (2014) Radiation Pneumonitis and Pulmonary Function with Lung Dose-Volume Constraints in Breast Cancer Irradiation. Journal of Radiotherapy in Practice, 13, 211-217. https://doi.org/10.1017/S1460396913000228 